\title{
Gas-Phase Acidities of Diols
}

\author{
Catherine A. Crowder* and John E. Bartmess \\ Department of Chemistry, Uriversity of Tennessee, Knoxville, Tennessee, USA
}

The gas-phase acidities of several $\alpha$, w-alkanediols were measured with the equilibrium method in an ion cyclotron resonance spectrometer. The values obtained imply cyclization of the structures via an intramolecular hydrogen bond. The results are in quantitative disagreement with those obtained by the method of dissociation of the excited dimer species; care must be used in applying that method to ensure that all of the criteria for relating kinetics to equilibria are met. (J Am Soc Mass Spectrom 1993, 4, 723-726)

$\mathrm{T}$ The determination of how a distant substituent interacts with a reactive site is ideally done utilizing a fairly rigid framework between site and substituent, so that the geometric relationship is fixed. When the framework can flex, so that the substituent can interact with the reactive site directly, via hydrogen bonding, the substituent effect would be expected to be much larger than for the rigid structure. In solution, interactions of the substituent and reactive sites with the solvent are such that the most stable form of the molecule is ustually an extended one, with the ends in separate solvation shells. In the gas phase, however, for ionic species, the ion-dipole or ionhydrogen bonding interactions will be the major forces present and will almost invariably result in cyclization of $\alpha, \omega$-substituted systems.

Yamdagni and Kebarle [1] investigated the gasphase basicities of a number of $\alpha$, $\omega$-diaminoalkanes $\left[\mathrm{NH}_{2}\left(\mathrm{CH}_{2}\right)_{n} \mathrm{NH}_{2}(n=2-7)\right]$ by equilibration in a proton transfer reaction with protonated monoamines. They found that diamines with $n \geq 3$ were considerably more basic $(\Delta G)$ than the corresponding $\mathrm{CH}_{3}\left(\mathrm{CH}_{2}\right)_{n} \mathrm{NH}_{2}$, presumably due to cyclization of the diamines to a proton-bridged structure, with attendant stabilization by the extra hydrogen bond. Variable temperature equilibrium studies indicated that the formation of the protonated diamine is accompanied by an entropy loss of $13-21 \mathrm{cal} / \mathrm{mol} \cdot \mathrm{K}$, consistent with the postulated cyclization. The calculated entropy loss for the cyclization of the diaminoalkanes reached a maximum when the ring size could accommodate a hydrogen bond of linear geometry, at appruximately $n=3$.

Likewise, Morton and Beauchamp [2] found that the extent of cyclization for the $\alpha$, $\omega$-dimethoxyalkanes

\footnotetext{
*Present address: EG \& G Inc, Idaho Falls, ID 83415

Address reprint requests to John E. Bartmess, Department of Chemistry, University of Tennessee, Knoxville, TN 37996-1600.
}

$\left[\mathrm{CH}_{3} \mathrm{O}\left(\mathrm{CH}_{2}\right)_{n} \mathrm{OCH}_{3}(n=2-6)\right]$ varied with ring size, with an apparent preference for larger rings, although quantitative values were not obtained. Similar results have been reported for other bifunctional species, such as amino alcohols [2-5], diketones [6] and amino acids $[5,7]$. Basicity studies of $\alpha$, $\omega$-diols were recently reported [8]; for 1,4-, 1,6-, and 1,8-alkanediols, the basicity is consistently $18-19 \mathrm{kcal} / \mathrm{mol}$ greater than that expected for the monoalcohol. The entropy of cyclization decreases by approximately $10 \mathrm{cal} / \mathrm{mol} \cdot \mathrm{K}$ for each $-\mathrm{CH}_{2} \mathrm{CH}_{2}-$ group added to the chain, and the enthalpy of cyclization becomes more negative by $3^{-4} \mathrm{kcal} / \mathrm{mol}$ for the same series.

There do not seem to be any equilibrium studies of anions that can cyclize in this fashion. We therefore measured the gas-phase acidities of a series of aliphatic diols $\left[\mathrm{HO}\left(\mathrm{CH}_{2}\right)_{n} \mathrm{OH}(n=2-5)\right]$, using ion cyclotron resonance (ICR) mass spectrometry [9]. It is known that the formation of an intermolecular hydrogen bond stabilizes an alkoxide-alcohol cluster ion such as $\mathrm{CH}_{3} \mathrm{OH} \cdot{ }^{-} \mathrm{OCH}_{3}$ (where the donor and acceptor are derived from the same alcohol) by approximately $28 \mathrm{kcal} / \mathrm{mol}$ in enthalpy but at a cost of $27 \mathrm{cal} / \mathrm{mol} \cdot \mathrm{K}$ in entropy [10]. If the anion of the diol is cyclizing by the formation of intramolecular hydrogen bonds, the diols would be expected to be more acidic by up to $21 \mathrm{kcal} / \mathrm{mol}$ in $\Delta \mathrm{G}_{\text {acid }}$ compared to monoalcohols of comparable molecular size. This value of $21 \mathrm{kcal} / \mathrm{mol}$ is based on the inlermolecular hydrogen bonding enthalpy of $28 \mathrm{kcal} / \mathrm{mol}$ [10] being an upper limit to the intramolecular value due to angle strain in the cyclized form. The entropy of clustering of $27 \mathrm{cal} / \mathrm{mol} \cdot \mathrm{K}$ is also an upper limit to that expected for cyclization: In large part, it represents loss of translational entropy [11] in the intermolecular case $\left(-34 \mathrm{cal} / \mathrm{mol} \cdot \mathrm{K}\right.$ for formation of $\left.\mathrm{CH}_{3} \mathrm{OH} \cdot{ }^{-} \mathrm{OCH}_{3}\right)$, which is balanced by a loss of free rotation on cyclization $(13-21 \mathrm{cal} / \mathrm{mol} \cdot \mathrm{K}$, as noted below for diamines [1]). 
A second motive for this work arises from a previous study of these diol acidities. Houriet et al. [12] examined gas-phase diol acidities using Cooks' method of dissociation of alkoxide-alcohol clusters [13]. Using the mass-analyzed ion kinetic energy spectrometry (MIKES) technique in a two-sector mass spectrometer, they measured the dissociation ratio of metastable $\left.n \mathrm{PrO}^{-} \cdot \cdot \mathrm{HO}_{(\mathrm{CH}}\right)_{n} \mathrm{OH}$ species, taking the logarithm of the ratio of $n \mathrm{PrO}$ to $\mathrm{HO}\left(\mathrm{CH}_{2}\right)_{n} \mathrm{O}^{-}$formed as proportional to the $\delta \Delta G_{\text {acis }}$ between 1-propanol and the diol. This method has been shown to yield reliable relative acidity data for monoalcohols [14]. The concentrations of the decomposition products can be directly related to their respective rate constants of formation, as shown by eq 1 , where $I$ is the ion intensity, and the $\Delta G_{\text {acid }}$ values are scaled to known values for monoalcohols $[14,15]$. This relationship,

$$
\ln \left\{I\left(A_{1}^{-}\right) / I\left(A_{2}^{-}\right)\right\}=\ln \left\{k_{1} / k_{2}\right\} \propto \delta \Delta G_{\text {acid }} / R T
$$

is based on the assumption that $k_{1}$ and $k_{2}$, the unimolecular rate constants for dissociation into the two possible products, behave in an identical manner as functions of the internal energy of the system. This assumption is justified by the use of narrow time/ energy domains due to the use of metastable ions and by the similarity between the types of bonds being broken in the dissociation of the proton-bound dimers. If competitive rearrangements and/or dissociations are possible, however, the quantification of results can be altered [14]. There is some question as to the structure of the dimer ion in such studies when dealing with diols. The dimer ion could have structures resembling 1,2 , or 3 , which on dissociation could lead to different product distributions and different $\Delta G_{\text {acid }}$ values. The acidity measurements in this study are by direct proton transfer equilibration, where structures analogous to 1-3 are transitions states and thus cannot affect the measured equilibrium acidities directly.

\section{Experimental}

The diols were obtained commercially and were used as received, with the exception of 1,5-pentanediol, which needed to be distilled prior to use. The ICR mass spectra obtained for the diols verified their purity. The anilines used as standard acids were distilled, and the oximes were sublimed prior to use.

The ICR spectrometer was previously described [9], and the usual techniques for determining relative gasphase acidities were followed [16]. Isoamyl nitrite was used as an electron ionization-generated source of isopentyl alkoxide, which then deprotonated the neutral diols. Samples of the diols were admitted into the hot spectrometer $\left(50-65^{\circ} \mathrm{C}\right)$ approximately $16 \mathrm{~h}$ prior to the collection of data to obtain stable pressures [17]. The elevated temperature was necessary to obtain stable pressures of the diols. These temperatures are near the limit of the present instrument's temperature range when inserted into the magnet, which precluded even higher lemperature variation of the equilibrium experiments, to obtain $\Delta H$ and $\Delta S$ from van't Hoff plots. Although a range of temperatures is indicated above, the exact temperature cited for each experiment in Table 1 was used in the data analysis of that experi-



1
2

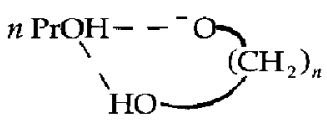

3

Table 1. Acidity data obtained by ICR spectrometry

\begin{tabular}{|c|c|c|c|c|c|c|c|}
\hline Diol & $\begin{array}{c}\delta \Delta \dot{G}_{a \mathrm{cid}}^{\mathrm{a}} \\
\text { (kcal/mal) }\end{array}$ & $\begin{array}{c}\text { Temp. } \\
\left({ }^{\circ} \mathrm{C}\right)\end{array}$ & $\begin{array}{c}\Delta G_{\mathrm{aceid}}^{\mathrm{b}} \\
\text { (kcal /mol) }\end{array}$ & $\begin{array}{c}\Delta S_{\text {acid }}^{c} \\
(\mathrm{cal} / \mathrm{mol}-\mathrm{k})\end{array}$ & $\begin{array}{c}\Delta H_{\mathrm{acid}}^{\mathrm{d}} \\
(\mathrm{kcal} / \mathrm{mol})\end{array}$ & $\Delta G_{\text {acid }}(\mathrm{ROH})^{\mathrm{e}}$ & $\delta \Delta G_{\mathrm{acid}}^{\dagger}$ \\
\hline 1.2-Ethanediol & $1.8>$ Aniline & 85 & 360.9 & 16.0 & 365.8 & 369.4 & -8.5 \\
\hline 1,3-Propanediol & $1.2<\mathrm{pF}$-aniline & 70 & 355.8 & 7.0 & 357.9 & 368.4 & -12.6 \\
\hline 1,4-Butanediol & $1.2<$ Pivaldoxime & 92 & 354.6 & 8.0 & 357.0 & 367.3 & -12.7 \\
\hline 1,5-Pentanediol & $1.6>\mathrm{mF}$-aniline & 89 & 355.5 & 8.0 & 357.9 & 366.5 & -11.0 \\
\hline
\end{tabular}

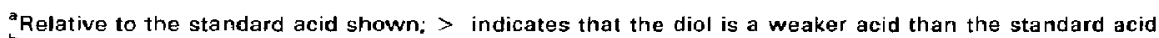

$\mathrm{b} \pm 2.0 \mathrm{kcal} / \mathrm{mol}$ absolute: $\pm 0.2 \mathrm{kcal} / \mathrm{mol}$ relative to other gas-phase acidities discussed here.

Estimated from eq 1, see text.

${ }^{d}$ From $\Delta G_{\text {acid }}+T * \Delta S_{\text {acid }}$. Uncertainty depends on assumptions used in estimating $\Delta S_{\text {scid }}$, see text.

${ }^{*} \Delta G_{\text {acid }}(\mathrm{kcal} / \mathrm{mol})$ for $\mathrm{Me}\left(\mathrm{CH}_{2}\right)_{r} \mathrm{OH}$, ref 16 .

Difference in $\Delta G_{\text {acid }}$ between $\mathrm{HO}\left(\mathrm{CH}_{2}\right)_{n} \mathrm{OH}$ and $\mathrm{Me}\left(\mathrm{CH}_{2}\right)_{n} \mathrm{OH}$. 
ment. The ionization gauge pressures were converted to true pressures using a calibration equation [18].

\section{Results}

Table 1 lists the acidities obtained for the diols. I'he values are anchored to the standard acidities reported in the literature [15]. Lacking direct measurement of $\Delta H$ and $\Delta S$, we used eq 2 to estimate the entropy of acidity, $\Delta S_{\text {acid }}$. This is taken as the sum of the entropy of acidity,

$$
\Delta S_{\text {acid }}(\text { diol })=\Delta S_{\text {acid }}(\text { mono })+\Delta S_{\text {cycl }}+\Delta S_{r}
$$

expected for the diol if it acted as a normal monoalcohol $(+22.0 \mathrm{cal} / \mathrm{mol} \cdot K[15,16])$, the loss of entropy on cyclization $\left(\Delta S_{\text {cycl }}\right)$ to an internally hydrogen-bonded structure, and any changes in symmetry number $(\sigma)$. The latter should essentially cancel for the diols $(\sigma=2)$, going to a cyclic structure with a rapidly exchanging proton $(\sigma=2)$ [19].

The values for $\Delta S_{\text {cycl }}$ are assumed to be comparable to those measured for the basicities of the corresponding $\alpha$, $\omega$-diamines [1]. It could be argued that the cyclization entropy for the anionic diols should be more negative than for the cationic diamines because the diamines might still rotate about the $\mathrm{C}-\mathrm{N}$ bond while swapping the hydrogen bond owing to the presence of additional hydrogens on the nitrogen atoms. The anionic diol has only one hydrogen in such a structure, and any rotation would result in a considerable enthalpic cost. This could result in a difference of up to $5 \mathrm{cal} / \mathrm{mol} \cdot \mathrm{K}$ if the cationic amine structures were freely rotating, and the anionic diol completely locked [11]. To the extent that this holds for any of the diols, $\Delta H_{\text {acid }}$ for that diol could be numerically $1.5 \mathrm{kcal} / \mathrm{mol}$ smaller than the value derived in Table 1.

There are several pieces of evidence that indicate that the diol alkoxides are in a cyclic form. Proton transfer from the diols to isopentyl alkoxide is rapid in the ICR spectrometer, at approximately $50 \%$ efficient. If the diols and their anions were in an acyclic form, they should have acidities comparable to that of isopentyl alcohol on the basis of known structural effects on acidities [15]. Proton transfer from the diol to isopentyl alkoxide should therefore be 0 to $+3 \mathrm{kcal} / \mathrm{mol}$ endothermic, in disagreement with the rapid transfer observed. The measured diol acidities indicate that such a proton transfer is instead 5-10 $\mathrm{kcal} / \mathrm{mol}$ exothermic, consistent with the observed kinetics. Also, appreciable amounts of [M $3 \mathrm{H}]^{-}$ions are formed, along with the $[\mathrm{M}-\mathrm{H}]^{-}$ion on deprotonation by isopentyl alkoxide, at intensities up to $30 \%$ of that for $[\mathrm{M}-\mathrm{H}]^{-}$. Such ions have been previously observed owing to pyrolysis of alcohols to enols or carbonyl compounds on hot surfaces in ICR spectrometers [20]. Such ions from pyrolytically produced neutrals are observed only in the unquenched made [21], however, owing to the extremely low con- centration of the neutral precursor. The $[\mathrm{M}-3 \mathrm{H}]^{-}$ ions observed here are formed in the quenched mode at rates comparable to that for production of the [M $\mathrm{H}]^{-}$ion and are therefore likely to come from the same reactive complex as the $[\mathrm{M}-\mathrm{H}]^{-}$ions. Their presence is also independent of whether the ionization gauge is on or off. If the $[\mathrm{M}-3 \mathrm{H}]^{-}$ions are enolates (e.g., $\mathrm{HOCH}_{2} \mathrm{CH}=\mathrm{CHO}^{-}$from 1,3-propanediol), then $\mathrm{H}_{2}$ loss should be approximately $5 \mathrm{kcal} / \mathrm{mol}$ endothermic from the open alkoxide. This energy is not available to an open alkoxide formed by deprotonation by isopentyl alkoxide $(+3 \mathrm{kcal} / \mathrm{mol}$ to thermoneutral for the proton transfer) but is available if the diol alkoxide cyclizes $(-5$ to $-10 \mathrm{kcal} / \mathrm{mol})$.

Finally, although exact rate constants for proton transfer were not determined, it was observed that it took considerably longer to attain equilibrium in the ICR spectrometer than for most acid/base systems of this type, based on the occurrence of a constant ratio of the two anion intensities [10]. This would be consistent with the proton being hydrogen bonded in the diol alkoxide [22].

\section{Discussion}

The diols $\left[\mathrm{HO}\left(\mathrm{CH}_{2}\right)_{n} \mathrm{OH}(n=2-5)\right]$ are $8-13 \mathrm{kcal} / \mathrm{mol}$ stronger as acids in terms of $\Delta G_{\text {acid }}$ than the corresponding $\mathrm{Me}\left(\mathrm{CH}_{2}\right)_{n} \mathrm{OH}$ alcohols. Part of this effect is due to the polar nature of the oxygen substituent: 2-Methoxyethanol is a stronger acid than 1-butanol

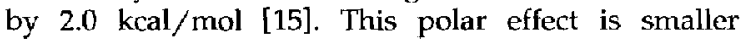
than the $8.5 \mathrm{kcal} / \mathrm{mol}$ acidity difference found for 1,2-ethanediol versus 1-propanol, however, and the polar effect should decrease as the hydroxy substituent becomes more distant. The strengthening of acidity over that expected from the polar effect can be attributed to the formation of intramolecular hydrogen bonds in the anions of the diols. Maximum strength $(12.7 \mathrm{kcal} / \mathrm{mol}$ in $\Delta G$ ) of the intramolecular hydrogen bond is found for 1,3-propanediol and 1,4-butanediol, which can form six- and seven-membered rings. This approaches the $21 \mathrm{kcal} / \mathrm{mol}$ for the intermolecular hydrogen bond in $\mathrm{CH}_{3} \mathrm{OH} \cdot{ }^{-} \mathrm{OCH}_{3}$ [10]. A sevenmembered ring can accommodate a linear hydrogen bond and is therefore expected to give maximum stability to the diol anion. The stronger acidity of all of the diols relative to the monoalcohols implies some degree of intramolecular hydrogen bonding for all of the diol anions studied.

Results for the anions of diols capable of forming rings with more than eight atoms could not be obtained using ICR spectrometry owing to the low vapor pressure and surface adherence of these diols; however. Houriet et al. [12] investigated aliphatic diols ( $n=$ 3-12) using the MIKES method and verified the afore mentioned assumptions for larger rings. They also

\footnotetext{
${ }^{1}$ Based on $\triangle H_{f}\left(\mathrm{CH}_{3} \mathrm{CH}_{2} \mathrm{CH}_{2} \mathrm{O}^{-}\right)=-50.6 \mathrm{kcal} / \mathrm{mol}$ and $\Delta H_{f}$ $\left(\mathrm{CH}_{3} \mathrm{CH}=\mathrm{CHO}-\right)=-45.2 \mathrm{kcal} / \mathrm{mol}$, from ref 15 .
} 
found that 1,4-butanediol had the largest strengthening of apparent acidity for the diols tested, relative to monoalcohols of comparable molecular weight and structure, with weaker $\delta \Delta G_{\text {acid }}$ values for rings smaller than seven atoms and in rings with more than eight atoms.

Table 2 compares the results for the diol acidities determined by direct equilibrium methods in the ICR spectrometer in this work and those from the dissociation of alkoxide-alcohol cluster ions using the MIKES method [12]. The MIKES results roughly parallel those obtained by $\mathrm{ICK}$ spectrometry, with respect to the ordering of the acidities of the three diols, showing the $\Delta G_{\text {acid }}$ order 1,4-diol $>1,5$-diol $>1,3$-diol; however, the acidities obtained from the MIKES method are consistently weaker by $4-7 \mathrm{kcal} / \mathrm{mol}$ than those from direct equilibration. The two methods agree quite well for monoalcohols [14], so that one of the assumptions made in relating the dissociation ratio in the MIKES method to the acidity appears to be invalid in this case. It is possible that the structure of the alkoxide-alcohol species that is the precursor for the MIKES method does not reflect the cyclized diol alkoxide minimum but, rather, is either an open structure or a mixture of open and cyclized populations. The kinetic method is known to give skewed results for dissimilar functional groups in the parent dimer [13]. It appears that even as subtle a difference as an internal hydrogen bond can bias the results. The internal temperature of the alkoxide-alcohol species in the metastable process may be sufficiently high that the cyclized form is not the stable form. In any case, it appears that use of the MIKES method for bifunctional compounds, at least of this type, leads to results that do not reflect the equilibrium situation.

\section{Conclusions}

On the basis of gas-phase acidities, w-hydroxy alkoxides $\left[\mathrm{HO}\left(\mathrm{CH}_{2}\right)_{n} \mathrm{O}^{-}(n=2-5)\right]$ appear to cyclize in the gas phase, with 1,4-butanediol being the most acidic diol in terms of free energy. Formation of the anions via deprotonation of the diols by strong bases also results in $\mathrm{H}_{2}$ loss. The method of dimer dissociation, used to determine relative acidities of other alcohols, does not agree with the equilibrium method for these diols, although the results are at least in the correct

Table 2 Comparison of $\Delta G_{\text {acid }}$ values obtained by ICR spectrometry and MIKES

\begin{tabular}{cccc} 
Diol & $\begin{array}{c}\text { ICR }^{\mathrm{a}} \\
\text { (kcal/mol) }\end{array}$ & $\begin{array}{c}\mathrm{MIKES}^{\mathrm{b}} \\
\text { (kcal/mol) }\end{array}$ & $\begin{array}{c}\delta \Delta G^{\mathrm{c}} \\
\text { (kcal } / \mathrm{mol})\end{array}$ \\
\hline 1.3-Propanediol & $\mathbf{3 5 5 . 8}$ & 363.1 & 7.3 \\
1,4-Butanediol & $\mathbf{3 5 4 . 6}$ & 359.5 & 4.9 \\
1,5-Pentanediol & 355.5 & 359.9 & 4.4 \\
\hline
\end{tabular}

${ }^{\mathrm{a}}$ This work, relative values $\pm 0.2 \mathrm{kcal} / \mathrm{mol}$.

bef $13, \pm 0.3 \mathrm{keal} / \mathrm{mal}$.

${ }^{\circ}$ Difference between MIKES and ICR results. ordering for the various diols. This should be taken into consideration when such experiments are performed, to be sure that the criteria for having the thermodynamics reflect the observed kinetics are adhered to.

\section{Acknowledgment}

We thank the National Science Foundation, CHE-8411164, for support of this work.

\section{References}

1. Yamdagni, R,; Kebarle, P. J. Am. Chem. Soc. 1973, 95, 3504.

2. Morton, T. J.; Beauchamp, J. L. I. Am. Chem. Soc. 1972, 94, 3671.

3. Aue, D. H.; Webb, M. H.; Bowers, M. T. J. Am. Chem. Soc. $1973,95,2699$.

4. Meot-Ner, M.; Hamlet, M.; Hunter, E. P.; Field, F. H. J. Am. Chem. Soc. 1980, 102, 6393 .

5. Wysocki, V. H.; Burinsky, D. J.; Cooks, R. G. I. Org. Chem. $1985,50,1287$.

6. Meot-Ner, M. I. Am. Chem. Soc. 1983, 105, 4906.

7. Meot-Ner, M. I. Ant. Chem. Soc. 1984, 106, 278.

8. Nicol, G. R.; Kebarle, P. Proceedings of the 40th ASMS Conference on Mass Spectrometry and Allied Topics; Washington, DC, May 31-June 5, 1992; p 160.

9. (a) McIver, R. T. Jr. Rev. Sci. Instrum. 1970, 41, 555; (b) McIver, R. T. Jr. Rev. Sci. Instrum. 1978, 49, 111; (c) McIver, R. T. Jr.; Hunter, R. L.; Ledford, E. B. Jr.; Locke, M. J.; Francl, T. J. Int. J. Mass Spectrom. Ion Phys. 1981, 39, 65; (d) Bartmess, J. E.; Caldwell, G. Int. Mass Spectrum. Ion Phys. 1981, 41, 125.

10. Meot-Ner, M.; Sieck, L. W. I. Phys. Chem. 1986, 90, 6687; (b) Caldwcll, G.; Rozeboom, M. D.; Kiplinger, J. P.; Bartmess, J. E. J. Am. Chem. Soc. 1984, $106,4660$.

11. Benson, 5. W. Thermochemical Kinetics, 2nd ed.; Wiley: New York, 1976; p 299.

12. Houriet, R.; Tabet, J.C.; Tchapla, A. Spectrosc. Int. 7. 1984, 3, 132.

13. (a) Cooks, R. G.; Kruger, T. L. J. Am. Chem. Soc. 1977, 99, 1279; (b) McLuckey, S. A.; Cameron, D.; Cooks, R. G. I. Am. Chem. Soc. 1981, 103, 1313.

14. Boand, G.; Houriet, R.; Gäumann, T. J. Am. Chem. Soc, 1983, $105,2203$.

15. Lias, S. G.; Bartmess, J. E.; Liebman, J. F.; Holmes, J. L.; Levin, R. D.; Mallard, W. G. I. Phys. Chem. Ref. Data 1988, strppl. 1, 17.

16. Bartmess, J. E.; Scott, J. A.; McIver, R. T. Jr. I. Am. Chem. Soc. 1979, 101, 6046.

17. Meot-Ner, M.; Sieck, L. W. Int. J. Mass Spectrom. Ion Processes 1991, 7119, 187.

18. Bartmess, J. E.; Georgiadis, R. M. Vacuum 1983, 33, 149.

19. Farneth, W. E.; Brauman, J. I. J. Am. Chem. Soc. 1976, 98, 7891; (b) Dodd, J. A.; Baer, S.; Moylan, C. R.; Brauman, J. I. J. Am. Chem. Soc. 1991, 113, 5942.

20. (a) Caldwell, G; Bartmess, J. E. Int. J. Mass Spectrom. Ion Phys. 1981, 40, 269; (b) Caldwell, G.; Bartmess, I. E. Int. J. Mass Spectrum. Ion Phys. 1983, 50, 235.

21. (a) Hunter, R. 1.; McIver, R. T. Jr. Anal. Chem. 1979, 51, 699; (b) Bartmess, J. E.; Caldwell, G. Int. J. Mass. Spectrom. Ion Phys. 1981, 41, 125.

22. Lloyd, J. R.; Agosta, W. C.; Field, F. H. I. Org. Chem. 1980, 45, 3483. 